\title{
Consumo, Digestibilidade e Parâmetros Ruminais em Tourinhos Limousin-Nelore, Suplementados Durante a Seca em Pastagem Diferida de Brachiaria decumbens Stapf ${ }^{1}$
}

\section{Eduardo Destéfani Guimarães Santos ${ }^{2}$, Mário Fonseca Paulino ${ }^{3}$, Sebastião de Campos Valadares Filho ${ }^{4}$, Rogério de Paula Lana ${ }^{4}$, Domingos Sávio Queiroz ${ }^{5}$, Dilermando Miranda da Fonseca ${ }^{4}$}

\begin{abstract}
RESUMO - Este trabalho foi realizado com o objetivo de estudar a influência de concentrados com diferentes teores de energia sobre consumo, digestibilidade aparente da matéria seca, $\mathrm{pH}$ e concentração de amônia do líquido ruminal em cinco tourinhos $\mathrm{F}_{1}$ LimousinNelore, com 18 meses e 286 kg de peso médio, fistulados no esôfago e rúmen. Os animais foram mantidos em pastagem de Brachiaria decumbens, durante a seca, e receberam apenas sal mineralizado, ou um dos tratamentos constituídos de 1,49\% de mistura mineral completa, 1,99\% uréia e diferentes proporções de milho quebrado, farelo de soja e farelo de trigo, com média de 24\% de PB e diferentes teores de carboidratos não fibrosos e de fibra em detergente neutro. Os suplementos foram fornecidos em quantidades equivalentes, em matéria original, a 1\% do peso vivo (PV). O consumo de matéria seca (CMS) dos animais suplementados, média de 2,05\% do PV (84,5 g MS/kg PV ${ }^{0,75}$ ), foi 42\% maior que o CMS dos animais não suplementados, média de 1,44\% do PV (57,7 g MS/kg PV 0,75$)$. O fornecimento de concentrados elevou em 55,4\% a digestibilidade da MS e em 60,4\% a concentração de energia digestível na dieta. O pH do líquido ruminal foi linear e negativamente influenciado pelo tratamento mais rico em milho quebrado, e linear e positivamente influenciado $(\mathrm{P}<0,05)$ pelo tratamento com maior proporção de farelo de trigo. A concentração de amônia ruminal manteve-se acima de $5 \mathrm{mg}$ de nitrogênio/100 mL de líquido ruminal, com exceção do tratamento em que os animais receberam apenas sal mineralizado.
\end{abstract}

Palavras-chave: amônia ruminal, capim-braquiária, consumo a pasto, pH do líquido ruminal, suplementação alimentar

\section{Intake, Digestibility and Ruminal Parameters in Young Bulls Limousin-Nelore, Supplemented During Dry Season in Brachiaria Decumbens Stapf Postponed Pasture}

ABSTRACT - The experiment was carried out to determine the supplements effects in the voluntary intake, digestibility, rumen pH and ammonia content of five 18 months old and $286 \mathrm{~kg}$ of live weight Nelore-Limousin young bulls, that received rumen and esophageal fistula. The treatments were: control, the animals received only mineral complex; and the others four were constituted by $1,49 \%$ of mineral complex, $1,99 \%$ of urea, and cracked corn, soybean meal and wheat bran different percentages. The treatments had $24 \%$ average crude protein, and non-fibrous carbohydrates and neutral detergent fiber different contents, and were provided on original matter basis, in amount equivalent to $1 \%$ of the weight. The animals that were submitted to the supplementary treatments exhibited similar DM intake and digestibility, and showed higher DMI and digestibility than the control group. The average dry matter intakes (DMI) were 2.05\% live weight ( $\mathrm{LW})\left(84.5 \mathrm{~g} \mathrm{DM} / \mathrm{kg} \mathrm{LW}{ }^{75}\right)$ and $1.44 \% \mathrm{LW}\left(57.7 \mathrm{~g} \mathrm{DM} / \mathrm{kg} \mathrm{LW}^{.75}\right)$ for supplemented animals and non-supplemented animals, respectively. The supplementation increased $42 \%$ the DMI, 55.4\% the dry matter digestibility and $60.4 \%$ the digestible energy content, in respect the non-supplemented animals diet. The ruminal fluid $\mathrm{pH}$ was influenced linear and positively by treatment with wheat bran amount, and linear and negatively by treatment with $75 \%$ cracked corn. The concentration of ruminal ammonia stayed above $5 \mathrm{mg}$ of nitrogen/100 $\mathrm{ml}$ of ruminal fluid, except for control treatment.

Key Words: pasture intake, pH, ruminal ammonia, signal grass, supplementation

\section{Introdução}

O consumo de alimentos é o principal processo relacionado com a produção animal e, associado à digestibilidade da dieta, determina a quantidade de nutrientes que pode ser usada para suprir diariamente as necessidades dos animais (NRC, 1984).

Na pastagem, normalmente, o aumento do tempo de pastejo é o recurso mais eficiente que o animal pode utilizar quando a taxa de ingestão de matéria

\footnotetext{
${ }^{1}$ Parte da dissertação de Mestrado apresentada pelo primeiro autor junto ao Depto. de Zootecnia da Universidade Federal de Viçosa.

2 Engenheiro-Agrônomo, MS. E.mail: edestefani1@hotmail.com.br

3 Professor orientador DZO - UFV, bolsista do CNPq. E.mail: mpaulino@ufv.br

${ }^{4}$ Professor DZO - UFV, bolsista do CNPq.

${ }^{5}$ Zootecnista, DS, pesquisador EPAMIG.
} 
seca é baixa ou está sendo reduzida. Entretanto, segundo Mannetje \& Ebersohn (1980), há limites na distância que os animais podem percorrer e no tempo que podem gastar no pastejo, diariamente, e esses fatores podem impedi-los de compensar as deficiências da pastagem com o prolongamento do período de alimentação. Assim, mesmo que os animais operem em seus limites físicos, o tempo máximo destinado ao pastejo pode ser insuficiente para que eles consumam pasto até o ponto de atenderem seus requerimentos energéticos ou mesmo de atingirem a repleção ruminal. Nesse caso, de acordo com Allden \& Whittaker (1970), os mecanismos que controlam o consumo em pastagens diferem daqueles que normalmente controlam o consumo por animais confinados.

Conforme Minson (1990), o CMS médio de forragem por ruminantes em pastagens tropicais é em torno de $50 \mathrm{~g}$ por kg de massa corporal metabólica $\left[\mathrm{g} /(\mathrm{kg} \text { de PV })^{0,75}\right.$. Segundo Preston \& Leng (1987), citados por Reis et al. (1997), o CMS de forragens tropicais por bovinos varia de 30 a $80 \mathrm{~g} /(\mathrm{kg} \mathrm{PV})^{0,75}$.

As restrições nutricionais impostas aos bovinos criados em pastagens tropicais, principalmente na estação seca, podem requerer dos sistemas de produção, que almejam terminação de animais durante o período seco ou, de forma geral, melhor taxa de produtividade, capacitação para ajustar suprimento com demanda de nutrientes. Nessas situações, se o consumo de pasto é baixo, a suplementação alimentar pode se tornar uma necessidade.

No entanto, o fornecimento de suplementos pode conduzir também a alterações, denominadas efeitos associativos, que se manifestam 1) no consumo de forragem; 2) na degradabilidade ruminal, na digestibilidade real e aparente; 3) nos locais de digestão da dieta; 4) na concentração de energia metabolizável; 5) nos produtos da fermentação; 6) no ganho de peso e na produção de leite (Moore et al., 1997).

A alteração no consumo de forragem por animais que recebem suplementos, chamada efeito de substituição, é medida pelo coeficiente de substituição (CS), definido como a razão entre decréscimo do CMS de forragem e CMS de suplemento. O CS é influenciado pelas características do animal, pelo tipo, pela qualidade e quantidade de suplemento fornecido, por época e manejo da suplementação e pelas características do relvado (Bowman \& Sowell, 1995, Moore et al., 1997). Conforme Reis et al. (1997), o CS varia normalmente entre 0,25 e 1,67, mas pode assumir valores negativos quando o suplemento estimula o consumo de forragem.

A redução do pH ruminal, freqüentemente citada como a maior causa da redução na digestibilidade da fibra, nem sempre explica decréscimos no consumo e na digestibilidade, associados com a suplementação de energia (Caton \& Dhuyvetter, 1997). O efeito do $\mathrm{pH}$ ruminal na digestibilidade da celulose tem sido freqüentemente confundido com alterações decorrentes do aumento no consumo de alimentos ou da concentração de fibra na dieta, fatores que também alteram a digestibilidade. O aumento na taxa de passagem normalmente reduz a digestibilidade dos componentes da dieta e, em especial, dos componentes mais resistentes à degradação, como a fibra e o amido de baixa degradabilidade ruminal (Russell \& Wilson, 1996). Baixa concentração ruminal de amônia e de AGV de cadeia ramificada, assim como deficiências minerais, também podem desencadear reduções na digestibilidade da dieta e no consumo de forragem.

Alimentos ricos em fibras prontamente degradáveis (FPD), como farelo de trigo, farelo de arroz, casca de soja e polpa de citros, têm sido utilizados em substituição total ou parcial aos grãos amiláceos na tentativa de se reduzir os efeitos da suplementação energética sobre $\mathrm{pH}$ do líquido ruminal, digestibilidade ruminal da fibra e consumo de forragem (Caton \& Dhuyvetter, 1997). Suplementos amiláceos e fontes de FPD diferenciam-se em características como teor de FDN e volume que ocupam no rúmen, massa específica (densidade), tempo de ingestão, tempo de hidratação, digestibilidade potencial e efetiva, taxas de digestão no rúmen e intestino delgado, taxas de passagem, quantidade e proporção dos produtos finais da fermentação e eficiência na utilização pelo animal. Em função dessas diferenças, misturas de FPD e de fontes de amido podem ser importantes para modular a fermentação ruminal no sentido de maximizar CMS, síntese de proteína bruta microbiana no rúmen, digestão e assimilação de energia e proteína, reduzindo perdas e aumentando a eficiência no uso dos nutrientes pelo animal.

Nesse contexto, o presente trabalho foi desenvolvido com o objetivo de estudar a influência do uso de concentrados, com diferentes teores de energia e de FPD, sobre consumo, digestibilidade da matéria seca e pH e concentração de amônia no líquido ruminal de bovinos em pastagens de Brachiaria decumbens, durante a estação seca.

\footnotetext{
R. Bras. Zootec., v.33, n.3, p.704-713, 2004
} 


\section{Material e Métodos}

Esse trabalho foi conduzido na Fazenda Experimental de Felixlândia (MG), pertencente à Empresa de Pesquisa Agropecuária de Minas Gerais (EPAMIG), no período de julho a setembro de 1997. Utilizou-se um campo de pastagem cultivada com Brachiaria decumbens, com área aproximada de 5,35 ha, e um curral anexo que dispunha de cochos e bebedouros. O diferimento da pastagem foi o recurso de manejo utilizado para aumentar a disponibilidade de forragem no período seco de 1997.

Foram utilizados cinco bovinos $\mathrm{F}_{1}$ Limousin-Nelore, não castrados, fistulados no esôfago e rúmen, com 18 meses de idade e peso médio de $286 \mathrm{~kg}$ no início do experimento. Após as cirurgias para colocação das fístulas em abril e maio de 1997, os animais foram mantidos em pastagem de Brachiaria decumbens por cerca de 30 dias para adaptação ao local e ao manejo. Em seguida, os animais foram distribuídos aleatoriamente em cinco tratamentos durante um período de 28 dias (período 1: 5 de agosto a 1ํ de setembro - referido também como agosto) e, posteriormente, redistribuídos aleatoriamente em um segundo período experimental (período 2: 2 a 29 de setembro - referido também como setembro) entre os mesmos cinco tratamentos.

O tratamento controle consistiu-se de mistura mineral completa, cuja composição foi: $50 \%$ de fosfato bicálcico; $48 \%$ de cloreto de sódio; $1,5 \%$ de sulfato de zinco; $0,4 \%$ de sulfato de cobre; $0,05 \%$ de sulfato de cobalto; $0,03 \%$ de iodato de potássio e $0,02 \%$ de sulfato de magnésio. A mistura mineral esteve disponível para consumo dos animais durante todo o experimento. Os demais tratamentos foram constituídos por mistura mineral completa, uréia e diferentes proporções de milho quebrado, farelo de soja e farelo de trigo. Na Tabela 1, estão apresentadas as composições porcentuais dos ingredientes que constituíram os tratamentos.

Os suplementos foram fornecidos em quantidades diárias de matéria original equivalentes a 1\% do PV dos animais. O horário estabelecido para a distribuição dos concentrados foi às $10 \mathrm{~h}$ e os suplementos foram fornecidos em cochos separados dentro do curral. À medida que os animais consumiam seus respectivos concentrados, eram liberados para a pastagem.

Amostras dos suplementos foram colhidas a cada 14 dias e ao final do experimento foram obtidas amostras compostas por tratamento. As análises de matéria seca (MS), proteína bruta (PB), extrato etéreo (EE), cinzas (CZ), lignina (LIG) e minerais por via úmida, cálcio $(\mathrm{Ca})$, fósforo $(\mathrm{P})$, potássio $(\mathrm{K})$ e magnésio (Mg) foram realizadas segundo Silva (1990) e as análises de fibra em detergente neutro (FDN) e ácido (FDA), segundo Van Soest et al. (1991). A digestibilidade in vitro da matéria seca (DIVMS) das amostras foi obtida conforme metodologia proposta por Tilley \& Terry (1963), adaptada por Silva (1990). Os carboidratos totais (CHT) foram obtidos, de acordo com Sniffen et al. (1992), segundo a fórmula: $\mathrm{CHT}(\% \mathrm{MS})=100-[\mathrm{PB}(\% \mathrm{MS})+\mathrm{EE}(\% \mathrm{MS})+\mathrm{CZ}$ (\%MS)].

A PB foi fracionada conforme Cornell Net Carbohydrate and Protein System (CNCPS), segundo Krishnamoorthy et al. (1982) e Licitra et al. (1996), em: fração A (CNNP - compostos nitrogenados não protéicos, rapidamente degradados no rúmen: amônia, peptídios e aminoácidos), obtida por solubilização em solução de ácido tricloroacético (TCA) a $10 \%$; fração $\mathrm{B}_{1}$ (proteína verdadeira solúvel, rapidamente degradada no rúmen), obtida deduzindo-se a proteína solúvel em TCA 10\% (fração A) da PB solúvel em tampão borato-fosfato; fração $\mathrm{B}_{2}$ (proteína insolúvel com taxa de degradação intermediária); fração $\mathrm{B}_{3}$ (proteínas associadas à parede celular; parcial e lentamente degradadas no rúmen); e fração $C$ ( $P B$ não disponível). $A$ fração $B_{3}$ foi estimada por meio da fórmula: $\mathrm{B}_{3}(\% \mathrm{~PB})=100 *$ [PIDN (\%MS) - PIDA (\%MS)]/PB (\%MS), sendo PIDN $[=6,25 *$ NIDN (\%MS)] a proteína insolúvel

Tabela - Composição percentual dos tratamentos Table 1 - Percentage composition of the treatments

\begin{tabular}{|c|c|c|c|c|c|}
\hline \multirow[t]{2}{*}{$\begin{array}{l}\text { Ingredientes }^{1} \\
\text { Ingredients }^{1}\end{array}$} & \multicolumn{5}{|c|}{$\begin{array}{c}\text { Tratamentos } \\
\text { Treatments }\end{array}$} \\
\hline & $\mathrm{T}_{1}$ & $\mathrm{~T}_{2}$ & $\mathrm{~T}_{3}$ & $\mathrm{~T}_{4}$ & $\mathrm{~T}_{5}$ \\
\hline $\begin{array}{l}\text { Mistura mineral } \\
\text { Mineral complex }\end{array}$ & 100,00 & 1,49 & 1,49 & 1,49 & 1,49 \\
\hline $\begin{array}{l}\text { Uréia } \\
\text { Urea }\end{array}$ & 0,00 & 1,99 & 1,99 & 1,99 & 1,99 \\
\hline $\begin{array}{l}\text { Farelo de soja } \\
\text { Soybean meal }\end{array}$ & 0,00 & 20,90 & 14,23 & 8,66 & 1,99 \\
\hline $\begin{array}{l}\text { Milho quebrado } \\
\text { Corn grain cracked }\end{array}$ & 0,00 & 75,62 & 50,45 & 25,17 & 0,00 \\
\hline $\begin{array}{l}\text { Farelo de trigo } \\
\text { Wheat bran }\end{array}$ & 0,00 & 0,00 & 31,84 & 62,69 & 94,53 \\
\hline
\end{tabular}

${ }^{1}$ Em matéria original.

1 In original matter basis. 
em detergente neutro e PIDA $[=6,25 *$ NIDA (\%MS)], proteína insolúvel em detergente ácido. NIDN (nitrogênio insolúvel em detergente neutro) foi estimado como nitrogênio total no resíduo de FDN, e NIDA (nitrogênio insolúvel em detergente ácido) no resíduo de FDA. A fração $\mathrm{C}$ foi determinada por meio da fórmula $\mathrm{C}(\% \mathrm{~PB})=100 * \mathrm{PIDA}(\% \mathrm{MS}) / \mathrm{PB}$ (\%MS) e a fração $B_{2}$ foi estimada por diferença.

Os CHT foram fracionados em carboidratos não fibrosos (CNF), equivalentes às frações $A$ e $B_{1}$ no sistema CNCPS; fração $\mathrm{B}_{2}$ (carboidratos estruturais, potencialmente digestíveis); e fração C (carboidrato indigestível no trato gastrintestinal dos ruminantes).

CNF foram calculados, de acordo com Kabeya (2000), a partir da fórmula: CNF (\%MS) $=[\mathrm{CHT}$ (\%MS) - FDNcp (\%MS)]; ou CNF (\%MS) = $1100-$ $[\mathrm{PB}(\% \mathrm{MS})+\mathrm{EE}(\% \mathrm{MS})+\mathrm{FDNcp}(\% \mathrm{MS})+\mathrm{CZ}$ (\%MS)]\}, em que FDNcp é FDN desprovida de cinzas e proteína; e a fração CNF $(\% \mathrm{CHT})=\{100 *$ [CNF (\%MS)/CHT (\%MS)]\}. A fração C de carboidratos nas amostras de concentrados foi estimada de acordo com Sniffen et al. (1992), em que C $(\% \mathrm{CHT})=[\mathrm{FDN}(\% \mathrm{MS}) * 2,4 *$ lignina $(\% \mathrm{FDN}) /$ CHT (\%MS)]. A fração $B_{2}$ de CHT foi obtida por diferença.

O CMS foi estimado a partir da produção fecal, verificada com auxílio do óxido crômico $\left(\mathrm{Cr}_{2} \mathrm{O}_{3}\right)$ como indicador externo (20g por dia) e da fibra em detergente neutro indigestível (FDNI) como indicador interno. O óxido crômico foi fornecido durante onze dias, sendo os seis primeiros para adaptação dos animais ao manejo e regularização da excreção do cromo nas fezes, e mais cinco dias durante a coleta de fezes. As fezes foram colhidas diretamente do reto, no mesmo horário da administração do indicador, às $10 \mathrm{~h}$.

Os teores de cromo nas amostras de alimentos e fezes foram determinados segundo Silva (1990). O teor de FDNI (indicador interno) foi obtido incubando-se as amostras com líquido ruminal e saliva artificial por 144 horas em uma única etapa e extraindo-se a FDN do resíduo indigestível após a incubação, de acordo com metodologia proposta por Cochran et al. (1986). O fator [FDNcp/FDN] foi multiplicado ao resultado obtido para correção do teor de FDNI em relação às cinzas e proteínas residuais (Gomes Jr., 2000).

A produção fecal foi estimada por meio da equação: $\mathrm{PF}=\mathrm{Cr}_{\text {adm. }} /[\mathrm{Cr}]_{\mathrm{FZ}}$; em que $\mathrm{Cr}_{\text {adm. }}$ = quantidade do indicador administrada diariamente por infusão contínua e $[\mathrm{Cr}]_{\mathrm{FZ}}=$ concentração de cromo nas fezes. O CMS foi, então, estimado por meio da fórmula:
$\mathrm{CMS}=\mathrm{CMS}_{\text {for }}+\mathrm{CMS}_{\text {supl }}=\{($ FDNI excretado nas fezes - FDNI ingerido no suplemento)/[FDNI $\left.]_{\text {for }}\right\}+$ $\mathrm{CMS}_{\text {supl }}$; sendo: $\mathrm{CMS}_{\text {for }}=\mathrm{CMS}$ de forragem; CMS = CMS de suplemento; $[\text { FDNI }]_{\text {for }}=$ concentração de FDNI na extrusa. Avaliou-se, também, o consumo de FDN (CFDN). As extrusas foram colhidas em 8 de agosto (período 1) e 9 de setembro 1997 (período 2), conforme metodologia descrita por Santos (2000).

As digestibilidades aparentes de matéria seca (DMS), matéria orgânica (DMO), proteína bruta (DPB), fibra em detergente neutro (DFDN) e energia bruta (DEB) foram obtidas de acordo com Coelho da Silva \& Leão (1979). Os valores de NDT (nutrientes digestíveis totais aparentes) foram obtidos adaptando-se as metodologias descritas por Coelho da Silva \& Leão (1979) e Sniffen et al. (1992), em que NDT $(\%$ MS $)=$ PB dig. $(\%$ MS $)+2,25 *$ EE dig. $(\%$ MS) + CHT dig. (\% MS).

As informações de CMS, CFDN, DMS, DMO, DPB, DFDN, DEB e NDT, obtidas durante cinco dias consecutivos por período experimental, foram avaliadas em delineamento com cinco tratamentos e dois blocos (período 1 e 2) e as médias, comparadas usando-se o teste de Tukey e $\alpha=5 \%$ de probabilidade.

Para a avaliação de pH e concentração ruminal de amônia, foram colhidas amostras de líquido ruminal às 0,2 , 4 e 6 horas após o fornecimento dos suplementos. Esse procedimento foi realizado fora dos períodos de administração de óxido crômico e colheita de fezes. As amostras de líquido ruminal foram imediatamente filtradas após a colheita, em dupla camada de gaze e, em seguida, determinados os valores de $\mathrm{pH}$, em peagâmetro digital. Retiraram-se alíquotas de $80 \mathrm{~mL}$ dessas amostras, que foram acidificadas com $2 \mathrm{~mL}$ de $\mathrm{HCl}(1: 1)$ e conservadas em congelador. A concentração de amônia no líquido ruminal foi determinada imediatamente após o descongelamento e centrifugação das amostras a 1.000 x G por 15 minutos, desprezando-se o precipitado. A determinação do nitrogênio total foi realizada segundo técnica descrita por Ferner (1965), adaptada por Vieira (1980), em aparelho micro-Kjeldahl, utilizando-se alíquota de $2 \mathrm{~mL}$ do líquido sobrenadante, ao qual se adicionaram $18 \mathrm{~mL}$ de água destilada e $15 \mathrm{ml}$ de $\mathrm{KCl}$ 2N. Destilou-se em $20 \mathrm{~mL}$ de ácido bórico até o volume de $100 \mathrm{~mL}$ e titulou-se com $\mathrm{HCl}$ 0,005N.

Os parâmetros ruminais, pH e concentração de amônia foram avaliados em delineamento de blocos casualizados, com cinco tratamentos e quatro blocos constituídos pelos tempos de colheita após o forneci-

\footnotetext{
R. Bras. Zootec., v.33, n.3, p.704-713, 2004
} 
mento dos suplementos. Para comparações entre médias usou-se o teste de Tukey; $\alpha=0,05$. Também foram ajustadas equações de regressão entre os parâmetros ruminais, pH e concentração de amônia, em função tempo de colheita da amostra após o fornecimento dos suplementos; $\alpha=0,05$.

\section{Resultados e Discussão}

Na Tabela 2, é apresentada a composição químico-bromatológica dos tratamentos. Os suplementos apresentaram teor de PB, em média, de $24 \%$, e diferentes teores de carboidratos não fibrosos (CNF), energia metabolizável e de FDN. À medida que a proporção de farelo de trigo foi aumentada no tratamento, houve diminuição do teor de energia metabolizável e de CNF e aumento do teor de FDN.

$\mathrm{O}$ tratamento $\mathrm{T}_{2}$ foi o mais rico em amido (no caso, o principal constituinte de CNF), com maior concentração de energia metabolizável e menor de FDN, enquanto o tratamento $T_{5}$ conteve menores concentrações de energia metabolizável e de amido, e maior teor de FDN. Na Tabela 3, são apresentadas as frações da PB e dos CHT nos concentrados, de acordo com os tratamentos.

A fração A da proteína (CNNP) nos concentrados correspondeu a mais de $33 \%$ da PB. Os suplementos ricos em farelo de trigo apresentaram maiores teores dessa fração protéica, sendo de 77, 82, 106 e 118 g/kg na MS nos tratamentos $\mathrm{T}_{2}, \mathrm{~T}_{3}, \mathrm{~T}_{4}$ e $\mathrm{T}_{5}$, respectivamente. Os suplementos mais ricos em milho apresentaram maiores teores de CNF; os teores dessa fração foram de 606, 517, 378 e $314 \mathrm{~g} / \mathrm{kg}$ na MS nos tratamentos $\mathrm{T}_{2}, \mathrm{~T}_{3}, \mathrm{~T}_{4}$ e $\mathrm{T}_{5}$, respectivamente. Considerando que aproximadamente $90 \%$ de CNF presente na MS do milho, farelo de soja e farelo de trigo seja amido, como afirma NRC (1996), as concentrações desse nutriente teriam correspondido a 545, 465, 340 e $283 \mathrm{~g} / \mathrm{kg}$ na MS dos tratamentos $\mathrm{T}_{2}, \mathrm{~T}_{3}, \mathrm{~T}_{4}$ e $\mathrm{T}_{5}$, respectivamente.

As médias de consumo são apresentadas na Tabela 4, de acordo com o tratamento. Foram observados efeitos significativos $(\mathrm{P}<0,05)$ do suplemento alimentar sobre o CMS. No entanto, não houve $(\mathrm{P}>0,05)$ efeito de bloco (período) sobre o CMS. O consumo dos animais suplementados foi, em média, 2,05\% do $\mathrm{PV}$ em MS (84,5 g MS/kg $\left.\mathrm{PV}^{0,75}\right)$, 42\% maior $(\mathrm{P}<0,05)$ que o dos animais não suplementados. Os animais suplementados consumiram, em média, 0,87\% do PV em MS de concentrados e 1,18\% do PV em
MS de forragem, com coeficiente de substituição médio (CS) igual a 0,29 .

O CMS dos animais não suplementados foi concordante com o valor médio de $50 \mathrm{~g} \mathrm{MS} /(\mathrm{kg} \mathrm{PV})^{0,75}$, mencionado por Minson (1990), para bovinos em

Tabela 2 - Teores de matéria seca (MS) em porcentagem da matéria original e de proteína bruta (PB), proteína insolúvel em detergente neutro (PIDN), proteína insolúvel em detergente ácido (PIDA), extrato etéreo (EE), cinzas (CZ), carboidratos totais $(\mathrm{CHT})$, carboidratos não fibrosos (CNF), fibra em detergente neutro (FDN), fibra em detergente ácido (FDA), lignina $(L I G)$, cálcio $(\mathrm{Ca})$, fósforo $(P)$, energia metabolizável (EM) e digestibilidade in vitro da matéria seca (DIVMS), em porcentagem da MS, de acordo com os tratamentos

Table 2 - Contents of dry matter (DM) in original matter percentage, and crude protein (CP), neutral detergent insoluble protein (NDIP), acid detergent insoluble protein $(A D I P)$, ether extract $(E E)$, ash, total carbohydrates (TC), non-fibrous carbohydrates (NFC), neutral detergent fiber (NDF), acid detergent fiber (ADF), lignin (LIG), calcium (Ca), phosphorus $(P)$, metabolizable energy (ME), and in vitro dry matter digestibility (IVDMD), in dry matter percentage, and according with the treatments

\begin{tabular}{|c|c|c|c|c|}
\hline \multirow[t]{2}{*}{$\begin{array}{l}\text { Itens } \\
\text { Items }\end{array}$} & \multicolumn{4}{|c|}{$\begin{array}{c}\text { Tratamento } \\
\text { Treatment }\end{array}$} \\
\hline & $\mathrm{T}_{2}$ & $\mathrm{~T}_{3}$ & $\mathrm{~T}_{4}$ & $\mathrm{~T}_{5}$ \\
\hline$\overline{\mathrm{MS}}$ & 86,17 & 87,10 & 86,84 & 86,29 \\
\hline$D M$ & & & & \\
\hline $\begin{array}{l}\mathrm{PB} \\
C P\end{array}$ & 23,13 & 23,67 & 24,27 & 25,35 \\
\hline $\begin{array}{l}\text { PIDN } \\
\text { NDIP }\end{array}$ & 1,84 & 1,66 & 2,89 & 3,27 \\
\hline PIDA & 0,29 & 0,42 & 0,46 & 0,53 \\
\hline $\begin{array}{l}A D I P \\
\mathrm{EE}\end{array}$ & 3,74 & 3,81 & 3,82 & 3,84 \\
\hline $\begin{array}{l}\text { CZ } \\
\text { Ash }\end{array}$ & 3,96 & 4,32 & 5,51 & 6,37 \\
\hline $\begin{array}{l}\text { CHT } \\
T C\end{array}$ & 69,17 & 68,21 & 66,39 & 64,44 \\
\hline $\begin{array}{l}\mathrm{CNF} \\
N F C\end{array}$ & 60,56 & 51,71 & 37,83 & 31,45 \\
\hline $\begin{array}{l}\text { FDN } \\
N D F\end{array}$ & 10,55 & 18,37 & 31,74 & 36,65 \\
\hline $\begin{array}{l}\text { FDA } \\
A D F\end{array}$ & 3,03 & 5,34 & 8,75 & 11,13 \\
\hline LIG & 0,49 & 1,23 & 2,72 & 3,05 \\
\hline Ca & 0,26 & 0,27 & 0,24 & 0,25 \\
\hline $\mathrm{P}$ & 0,67 & 0,77 & 1,05 & 1,36 \\
\hline $\begin{array}{l}\mathrm{EM}^{1} \\
M E^{1}\end{array}$ & 3,093 & 2,878 & 2,667 & 2,452 \\
\hline $\begin{array}{l}\text { DIVMS } \\
\text { IVDMD }\end{array}$ & 91,30 & 87,76 & 85,48 & 81,77 \\
\hline
\end{tabular}

${ }^{1} \mathrm{Em} \mathrm{Mcal} / \mathrm{kg}$ MS, de acordo com NRC (1996).

1 In Mcal/kg DM, according NRC (1996). 
pastagens tropicais, e também com os valores relatados por Adu \& Adamu (1982) e Reis et al. (1990), citados por Reis et al. (1997), referentes a bovinos em pastagens de Brachiaria decumbens maduras, cujos consumos foram de 58,5 e 53,3 g MS/kg PV $\mathrm{PV}^{0,75}$, respectivamente. O consumo médio dos animais suplementados foi semelhante aos valores observados por Gomes Jr. (2000), de 2,1\% do PV em MS, e Kabeya (2000), de 2,02 a 2,34\% do PV em MS, suplementando novilhos em pastagens maduras de Brachiaria decumbens.

O consumo médio de forragem dos animais não suplementados foi de apenas $115 \mathrm{~kg}$ de MS/animal em 28 dias, valor equivalente a 1,3\% da forragem disponível na pastagem, que era de $8.250 \mathrm{~kg} / \mathrm{ha}$, média nos dois períodos avaliados, considerando área pastejada por animal igual a 1,07 ha (5,35 ha/5 animais). Igualmente, os animais suplementados consumiram, em média, 1,18\% do PV em forragem. Esse valor foi equivalente ao consumo de $95 \mathrm{~kg}$ de MS de pasto/animal em 28 dias ou a 1,1\% da forragem disponível nos períodos avaliados. Provavelmente, esses resultados refletiram a dificuldade dos animais em colher forragem em pastagens tropicais maduras, durante a época seca, situação caracterizada por baixa proporção de folhas verdes no relvado, apenas

Tabela 3 - Frações protéicas $A, B_{1}, B_{2}, B_{3}$ e $C$ e de carboidratos totais $\mathrm{CNF}, \mathrm{B}_{2}$ e $\mathrm{C}$, dos concentrados correspondentes aos tratamentos

Table 3 - Protein fractions $A, B_{1}, B_{2}, B_{3}$ e $C$ and total carbohydrates fractions $C N F, B_{2}$ e $C$, according to the treatment

\begin{tabular}{lllll}
\hline \multicolumn{3}{c}{ the treatment } \\
Itens & \multicolumn{4}{c}{$\begin{array}{c}\text { Tratamentos } \\
\text { Treatments }\end{array}$} \\
\cline { 2 - 5 } & $\mathrm{T}_{2}$ & $\mathrm{~T}_{3}$ & $\mathrm{~T}_{4}$ & $\mathrm{~T}_{5}$ \\
\hline
\end{tabular}

Frações protéicas (\% PB)

Protein fractions (\% CP)

\begin{tabular}{ccccc}
$\mathrm{A}$ & 33,24 & 34,50 & 43,80 & 46,45 \\
$\mathrm{~B}_{1}$ & 8,71 & 13,61 & 9,06 & 8,80 \\
$\mathrm{~B}_{2}$ & 50,09 & 44,88 & 35,25 & 31,85 \\
$\mathrm{~B}_{3}$ & 6,69 & 5,19 & 9,84 & 10,80 \\
$\mathrm{PIDA}$ & 1,26 & 1,82 & 2,05 & 2,10 \\
$\mathrm{ADIP}$ & & & & \\
\hline
\end{tabular}

\begin{tabular}{|c|c|c|c|c|}
\hline \multirow[b]{2}{*}{ CNF } & \multicolumn{4}{|c|}{$\begin{array}{l}\text { Frações carboidratos totais (\% CHT) } \\
\text { Total carbohydrates fractions (\% TC) }\end{array}$} \\
\hline & & & & \\
\hline$N F C$ & 87,55 & 75,81 & 56,98 & 48,80 \\
\hline $\mathrm{B}_{2}$ & 12,01 & 20,89 & 34,20 & 37,58 \\
\hline $\mathrm{C}^{2}$ & 0,44 & 3,29 & 8,82 & 13,63 \\
\hline
\end{tabular}

14,5\%, e grande proporção de material morto, em média, 55,9\% da forragem disponível. Além da baixa disponibilidade de folhas verdes e alta de material morto, os baixos teores de PB (abaixo de $1 \%$ de $\mathrm{N}$ na MS) e os altos de FDN e lignina caracterizaram a baixa qualidade da forragem disponível (Santos, 2000).

O CFDN foi limitado a valores próximos a 1\% do PV e, apesar do menor CMS do grupo referência, foi semelhante $(\mathrm{P}>0,05)$ entre os animais suplementados e não suplementados, embora valores ligeiramente maiores fossem verificados nos tratamentos com maior proporção de farelo de trigo, ricos em FPD. A análise desses resultados parece sugerir que o CMS, nos períodos considerados, teria sido limitado pela repleção ruminal, em decorrência da baixa qualidade da forragem consumida. Isto significa inferir, também, que o requerimento de energia dos animais, inclusive dos suplementados, não teria sido atendido na sua totalidade. Na Tabela 5 são apresentadas as estimativas de digestibilidade da dieta e NDT.

A DMS da dieta consumida pelos animais suplementados foi, em média, $55,4 \%$ superior $(\mathrm{P}<0,05)$ à do pasto. Esse resultado era esperado em virtude da maior digestibilidade dos concentrados frente a da forragem colhida pelos animais. A digestibilidade negativa da $\mathrm{PB}$ no tratamento testemunha indica balanço negativo desse nutriente, que, provavelmente, deve ter afetado o CMS e a DMS da dieta ingerida pelos animais não suplementados.

Os valores de DFDN foram semelhantes ( $\mathrm{P}>0,05)$ em todos os tratamentos, a despeito, inclusive, da alta digestibilidade potencial da fibra dietética dos suplementos ricos em FPD. O aumento do CMS, proporcionado pela suplementação, pode ter contribuído para a redução da digestibilidade da fibra dietética nos animais suplementados. Outro fator que pode ter contribuído para que não fossem verificadas diferenças significativas na DFDN das diversas dietas foi a deficiência em nitrogênio no pasto, fato reconhecidamente depressor da atividade celulolítica ruminal. O teor de energia digestível na dieta consumida pelos animais suplementados foi $60,4 \%$ maior $(\mathrm{P}<0,05)$ que o verificado no pasto.

O teor médio de NDT verificado no pasto representa valor característico de dietas de baixa qualidade e, provavelmente, influiu no baixo CMS dos animais não suplementados. Os maiores valores de DMS, DMO, DPB e DEB apresentados no tratamento $\mathrm{T}_{3}$, embora não diferissem $(\mathrm{P}>0,05)$ nos demais tratamentos com concentrados, podem ser

R. Bras. Zootec., v.33, n.3, p.704-713, 2004 
indicativo de que a mistura de suplementos amiláceos e de FPD possibilitou ajuste ligeiramente melhor entre o poder fermentativo dos carboidratos e a disponibilidade de $\mathrm{N}$ para o rúmen nas condições em que o experimento foi desenvolvido.

Na Tabela 6, estão apresentadas as médias e equações de regressão ajustadas e seus respectivos coeficientes de determinação para o pH e concentração de amônia no líquido ruminal. Os parâmetros ruminais foram verificados no início do mês de agosto, quando a pastagem ainda permitia bom consumo de forragem.

O suplemento $\mathrm{T}_{2}$, mais rico em milho quebrado e farelo de soja, influenciou $(\mathrm{P}<0,05)$ o $\mathrm{pH}$ ruminal de forma linear e negativa em função do tempo de colheita, atingindo o valor mínimo de 5,72, em 6 horas após o início da ingestão do suplemento; enquanto o tratamento $\mathrm{T}_{5}$ influenciou $(\mathrm{P}<0,05)$ o $\mathrm{pH}$ linear e positivamente em função do tempo, atingindo o valor máximo de 6,98 em 6 horas após o fornecimento dos concentrados. $\mathrm{O} \mathrm{pH}$ do líquido ruminal nos animais dos tratamentos $\mathrm{T}_{1}, \mathrm{~T}_{3}$ e $\mathrm{T}_{4}$, não foi influenciado $(\mathrm{P}>0,05)$ pelo tempo de colheita após o fornecimento dos suplementos.

Com exceção do tratamento $\mathrm{T}_{2}$, os valores de $\mathrm{pH}$ do líquido ruminal mantiveram-se acima de 6,2, considerado por Orskov (1988) como limite mínimo para adequada fermentação da fibra. No entanto, como comentado anteriormente, não se observou redução da DFDN da dieta consumida no tratamento $\mathrm{T}_{2}$.

Paulino et al. (2002) observaram redução do pH ruminal em bovinos Holandês-Zebu com o fornecimento de $4 \mathrm{~kg}$ de suplementos a base de milho moído e farelo de soja por dia, em situação semelhante ao verificado neste trabalho para o tratamento $\mathrm{T}_{2}$. A equação de regressão ajustada $\left(\mathrm{Y}=6,9085-0,0670^{*} \mathrm{X}\right)$ foi também muito semelhante à verificada no presente trabalho.

Uma vez que os animais foram mantidos presos aos cochos durante todo o tempo de amostragem (6 horas), esses resultados podem ter sido influenciados pela velocidade de ingestão do suplemento e pelo impedimento ao consumo de forragem durante o tempo de amostragem. As conseqüências seriam maiores sobre os animais dos suplementos consumidos a taxas mais rápidas, como o $\mathrm{T}_{2}$. $\mathrm{O}$ impedimento ao consumo de forragem, naquele momento, pode ter aumentado a degradabilidade efetiva ruminal dos concentrados.

Poder-se-ia esperar que os suplementos ricos em farelo de trigo também influenciassem negativamente o pH ruminal, uma vez que a taxa de digestão ruminal do amido de farelo de trigo é mais alta e a taxa de passagem das partículas desse alimento do rúmen para o trato gastrintestinal inferior, mais baixa que do

Tabela 4 - Consumos médios diários de matéria seca total (CMS), expressos em porcentagem do peso vivo (\% PV) e em massa de MS por unidade de tamanho metabólico (g de $\mathrm{MS} /\left(\mathrm{kg} \mathrm{PV}^{0,75}\right)$ ), consumos de matéria seca de suplementos (CMSsupl) e consumos de fibra em detergente neutro (CFDN), relação volumoso:concentrado e coeficientes de substituição (CS), obtidos para os cinco tratamentos

Table 4 - Means of dry matter intake (DMI), expressed in the live weight percentage (\% LW) and metabolic weight $\left(g\right.$ of $\left.D M /(k g L W)^{0,75}\right)$, and dry matter of supplements intake (DMSI), neutral detergent fiber intake (NDFI), forage:concentrate ratio and coefficient of substitution (CS), obtained in the treatments

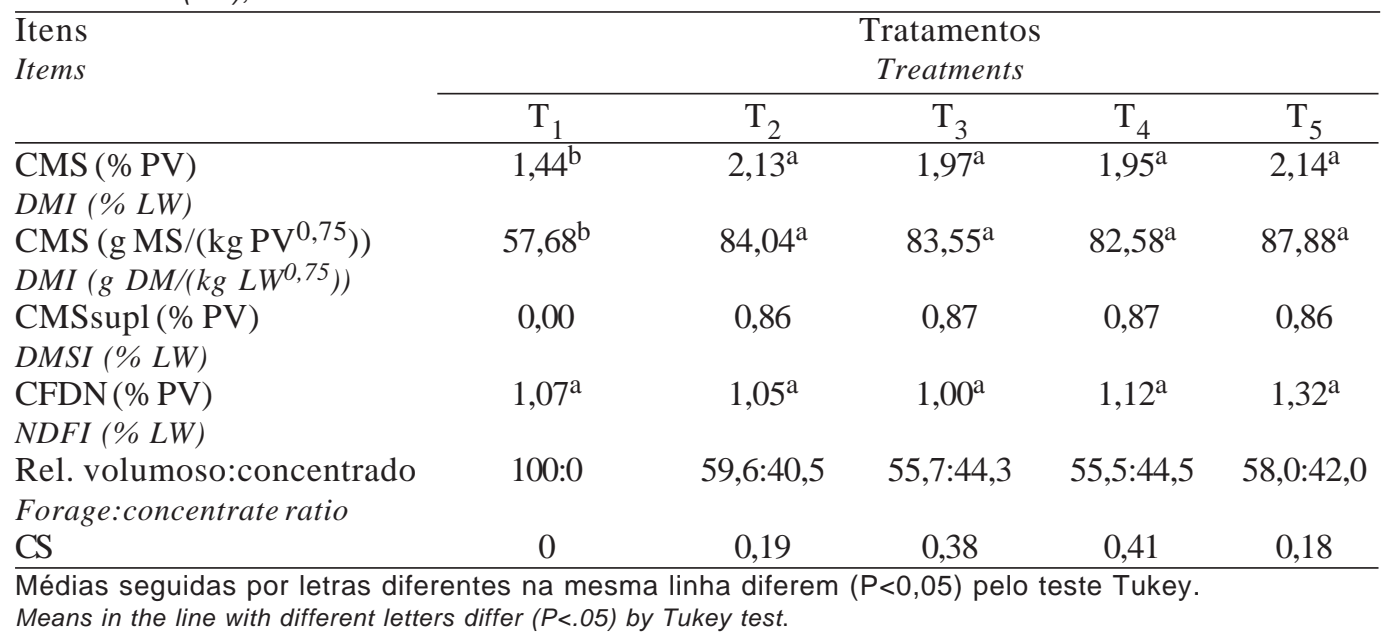

R. Bras. Zootec., v.33, n.3, p.704-713, 2004 
milho quebrado. De acordo com Sniffen et al. (1992), as taxas de digestão ruminal do amido de milho quebrado, farelo de soja e trigo são, respectivamente, 10-20, 40-50 e 60-85\%/hora, o que evidencia que o amido de trigo é, em média, seis vezes mais degradável no rúmen que o amido de milho quebrado. Portanto, o consumo de grande quantidade de farelo de trigo,

Tabela 5 - Médias de digestibilidades aparentes de matéria seca (DMS), matéria orgânica (DMO), proteína bruta (DPB), fibra em detergente neutro (DFDN) e energia bruta (DEB) e teor de nutrientes digestíveis totais aparente (NDT), obtidos para cada tratamento

Table 5 - Means of dry matter (DMD), organic matter (OMD), crude protein (CPD), neutral detergent fiber (NDFD) and gross energy (GED) digestibility, and average contents of total digestible nutrients (TDN), obtained in the treatments

\begin{tabular}{ccccccc}
\hline Tratamento & DMS & DMO & DPB & DFDN & DEB & NDT \\
Treatment & $D M D$ & OMD & $C P D$ & NDFD & DGE & $T D N$ \\
\hline \multicolumn{7}{c}{$\%$ Matéria seca } \\
$\%$ Dry matter \\
$\mathrm{T}_{1}$ & $35,6^{\mathrm{b}}$ & $38,8^{\mathrm{b}}$ & $-24,4^{\mathrm{b}}$ & $45,7^{\mathrm{a}}$ & $33,2^{\mathrm{b}}$ & $34,8^{\mathrm{b}}$ \\
$\mathrm{T}_{2}$ & $57,0^{\mathrm{a}}$ & $59,9^{\mathrm{a}}$ & $65,9^{\mathrm{a}}$ & $46,1^{\mathrm{a}}$ & $54,9^{\mathrm{a}}$ & $55,2^{\mathrm{a}}$ \\
$\mathrm{T}_{3}$ & $58,4^{\mathrm{a}}$ & $61,2^{\mathrm{a}}$ & $79,1^{\mathrm{a}}$ & $43,7^{\mathrm{a}}$ & $55,8^{\mathrm{a}}$ & $56,4^{\mathrm{a}}$ \\
$\mathrm{T}_{4}$ & $50,7^{\mathrm{a}}$ & $54,5^{\mathrm{a}}$ & $69,3^{\mathrm{a}}$ & $42,5^{\mathrm{a}}$ & $48,0^{\mathrm{a}}$ & $50,0^{\mathrm{a}}$ \\
$\mathrm{T}_{5}$ & $55,5^{\mathrm{a}}$ & $58,1^{\mathrm{a}}$ & $77,5^{\mathrm{a}}$ & $48,4^{\mathrm{a}}$ & $54,1^{\mathrm{a}}$ & $53,1^{\mathrm{a}}$
\end{tabular}

Médias seguidas por letras diferentes na mesma coluna diferem $(\mathrm{P}<0,05)$ pelo teste de Tukey.

Means in the column with different letters differ $(P<.05)$ by Tukey test. que é classificado como alimento rico em FPD, pode também resultar na produção de quantidades consideráveis de AGV e lactato, aumentando as concentrações desses metabólitos e reduzindo o $\mathrm{pH}$ e a concentração de amônia no rúmen.

Assim, a rapidez na ingestão do suplemento, o CMS e a relação volumoso:concentrado desempenham papéis importantes sobre os parâmetros ruminais. Baixo consumo do volumoso poderia resultar em maior retenção e digestão ruminal do suplemento e aumento da produção total de $\mathrm{AGV}$, da proporção molar de propionato e butirato e da demanda por proteína degradável no rúmen (PDR), afetando também a concentração de amônia no líquido ruminal.

Embora o tempo após fornecimento dos concentrados afetasse $(\mathrm{P}<0,05)$ as concentrações de amônia no líquido ruminal, não foram verificadas correlações entre essas duas variáveis $(\mathrm{P}>0,05)$. Em média, a concentração ruminal de amônia foi menor $(\mathrm{P}<0,05)$ no tempo imediatamente antes do fornecimento dos concentrados. Com exceção do tratamento $\mathrm{T}_{1}$, os demais apresentaram concentrações de amônia superiores a $5 \mathrm{mg}$ de $\mathrm{N}-\mathrm{NH}_{3} / 100 \mathrm{~mL}$ de líquido ruminal, aceito com o limite mínimo para adequada fermentação de alimentos fibrosos, conforme NRC (1984).

A baixa concentração ruminal de amônia no tratamento $\mathrm{T}_{1}$ pode ser justificada pelo baixo teor de nitrogênio na forragem consumida. E, entre os animais suplementados, a menor concentração média de amônia ruminal proporcionada pelo tratamento $\mathrm{T}_{5}$, que não

Tabela 6 - Médias e equações de regressão ajustadas para pH e concentração de amônia (mg de $\mathrm{N} / \mathrm{dL}$ ) no líquido ruminal, em função do tempo de colheita $(\mathrm{X})$, de acordo com o tratamento

Table 6 - Means and fitted regression equations for $\mathrm{pH}$ and ammonia concentration ([N-NH$]$ ) in the ruminal liquid, in function of sampling time $(X)$ and treatments

\begin{tabular}{|c|c|c|c|c|}
\hline $\begin{array}{l}\text { Item } \\
\text { Item }\end{array}$ & $\begin{array}{c}\text { Tratamento } \\
\text { Treatment }\end{array}$ & $\begin{array}{l}\text { Médias } \\
\text { Means }\end{array}$ & $\begin{array}{c}\text { Equações ajustadas } \\
\text { Fitted equations }\end{array}$ & $\mathrm{r}^{2}$ \\
\hline $\mathrm{pH}$ & $\begin{array}{l}\mathrm{T}_{1} \\
\mathrm{~T}_{2} \\
\mathrm{~T}_{3} \\
\mathrm{~T}_{4} \\
\mathrm{~T}_{5}\end{array}$ & $\begin{array}{l}7,13^{\mathrm{a}} \\
5,92^{\mathrm{c}} \\
6,44^{\mathrm{b}} \\
6,58^{\mathrm{b}} \\
6,74^{\mathrm{b}}\end{array}$ & $\begin{array}{c}\text { n.s. } \\
\mathrm{Y}=6,128-0,0685^{*} \mathrm{X}^{1} \\
\text { n.s. } \\
\text { n.s. } \\
\mathrm{Y}=6,508+0,0765^{*} \mathrm{X}^{1}\end{array}$ & $\begin{array}{c}== \\
0,99 \\
== \\
== \\
0,99\end{array}$ \\
\hline$\left[\mathrm{N}-\mathrm{NH}_{3}\right]$ & $\begin{array}{l}\mathrm{T}_{1} \\
\mathrm{~T}_{2} \\
\mathrm{~T}_{3} \\
\mathrm{~T}_{4} \\
\mathrm{~T}_{5}\end{array}$ & $\begin{array}{c}2,87^{\mathrm{b}} \\
24,35^{\mathrm{a}} \\
30,61^{\mathrm{a}} \\
29,46^{\mathrm{a}} \\
16,38^{\mathrm{ab}}\end{array}$ & $\begin{array}{l}\text { n.s. } \\
\text { n.s. } \\
\text { n.s. } \\
\text { n.s. } \\
\text { n.s. }\end{array}$ & $\begin{array}{l}== \\
== \\
== \\
== \\
==\end{array}$ \\
\hline
\end{tabular}

Médias seguidas por letras diferentes na mesma linha diferem $(P<0,05)$ pelo teste Tukey.

Means in the line with different letters differ $(P<.05)$ by Tukey test.

${ }^{1} \mathrm{~F}$ significativo a $5 \%$.

${ }^{1} \mathrm{~F}$ significant at $5 \%$.

R. Bras. Zootec., v.33, n.3, p.704-713, 2004 
diferiu $(\mathrm{P}>0,05)$ do $\mathrm{T}_{1}$, pode ser indicativo de que esse nutriente teria sido mais retido na forma de proteína microbiana, já que esse concentrado apresentava $55,3 \%$ da $\mathrm{PB}$ nas frações $\mathrm{A}$ e $\mathrm{B}_{1}$, e menor taxa de passagem (Sniffen et al., 1992) entre os suplementos utilizados.

\section{Conclusões}

O fornecimento de concentrados energéticoprotéicos, em quantidade equivalente a $1 \%$ do peso dos animais, incrementou o consumo em $42 \%$, a digestibilidade, em 55,4\% e a concentração de energia digestível na dieta, em 60,4\%.

O consumo de FDN, próximo de 1\% do PV do animal, foi muito semelhante entre os animais suplementados e não suplementados, sugerindo que o consumo alimentar teria sido limitado pela repleção ruminal e, portanto, o requerimento de energia dos animais, inclusive dos animais suplementados, não teria sido atendido na sua totalidade.

O valor negativo de digestibilidade da proteína no tratamento testemunha foi indicativo de que a deficiência protéica da forragem, além de causar balanço negativo de proteína, afetou o consumo e a digestibilidade do pasto durante o período estudado.

A suplementação energético-protéica, em quantidade equivalente a $1 \%$ do peso do animal, com exceção do tratamento mais rico em milho quebrado, não reduziu os valores de $\mathrm{pH}$ abaixo dos limites favoráveis ao consumo e à digestão de forragem. A suplementação também foi importante no aumento da concentração de amônia ruminal, que, nos animais suplementados, se manteve acima do limite mínimo para adequada fermentação de alimentos fibrosos.

\section{Literatura Citada}

ALLDEN, W.G.; WHITTAKER, I.A.M. The determinants of herbage intake by grazing sheep: the interrelationship of factors influencing herbage intake and availability. Australian Journal Agriculture Research, v.21, n.5, p.755-766, 1970.

BOWMAN, J.G.P.; SOWELL, B.L.F.L.; PATERSON, J.A. Liquid supplementation for ruminants fed low-quality forage diets: a review. Animal Feed Science and Technology, v.55, p.105-138, 1995.

CATON, J.S.; DHUYVETTER, D.V. Influence of energy supplementation on grazing ruminants: requirements and responses. Journal of Animal Science, v.75, p.533-542, 1997.

COCHRAN, R.C.; ADAMS, D.C.; WALLACE, J.D. et al. Predicting digestibility of different diets with internal markers: evaluation of four potential markers. Journal of Animal Science, v.63, n.5, p.1469-1475, 1986.
COELHO da SILVA, J.F.; LEÃO, M.I. Fundamentos da nutrição dos ruminantes. Piracicaba: Livroceres, 1979. 384p.

GOMES JR., P. Composição químico-bromatológica da Brachiaria decumbens e desenvolvimento de novilhos em recria suplementados durante a seca. Viçosa, MG: Universidade Federal de Viçosa, 2000. 51p. Dissertação (Mestrado em Zootecnia) - Universidade Federal de Viçosa, 2000.

KABEYA, K.S. Composição químico-bromatológica de gramíneas tropicais e desempenho de novilhos suplementados a pasto. Viçosa, MG: Universidade Federal de Viçosa, 2000. 74p. Dissertação (Mestrado em Zootecnia) - Universidade Federal de Viçosa, 2000.

KRISHNAMOORTHY, U.; MUSCATO, T.V.; SNIFFEN, C.J.; et al. Nitrogen fractions in selected feedstuffs. Journal of Dairy Science, v.65, p.217-225, 1982.

LICITRA, G.; HERNANDEZ, T.M.; Van SOEST, P.J. Standardization of procedures for nitrogen fractionation of ruminant feeds. Animal Feed Science and Technology, v.57, p.347-358, 1996.

MANNETJE, L, EBERSOHN, J.P. Relations between sward characteristics and animal production. Tropical Grasslands, v.14, n.3, p.273-280, 1980.

MINSON, D.J. Forage in ruminant nutrition. San Diego: Academic Press, 1990. 483p.

MOORE, J.E.; KUNKLE, W.E.; ROCHINOTTI, D. et al. Associative effects: are they real (?) and accounting for them in ration formulation. In: CORNELL NUTRITION CONFERENCE FOR FEED MANUFACTURERS, 1997, Ithaca, N.Y. Proceedings... Ithaca: Cornell University, 1997. p.1-10.

NATIONAL RESEARCH COUNCIL - NRC. Nutrient requirements of beef cattle. 6 rev.ed. Washington, D.C.: National Academy Press, 1984. 90p.

NATIONAL RESEARCH COUNCIL - NRC. Nutrient requirements of beef cattle. 7 rev. ed. Washington, D.C.: National Academy Press, 1996. 242p.

ORSKOV, E.R. Nutrición proteica de los rumiantes. Zaragoza: Acribia, 1988. 178p.

PAULINO, M.P.; DETMANN, E.; VALADARES FILHO, S.C. et al. Soja grão e caroço de algodão em suplementos múltiplos para terminação de bovinos mestiços em pastejo. Revista Brasileira de Zootecnia, v.31, n.1, p.484-491, 2002.

REIS, R.A.; RODRIGUES, L.R.A.; PEREIRA, J.R.A. A suplementação como estratégia de manejo da pastagem. In: SIMPÓSIO SOBRE MANEJO DA PASTAGEM, 13., 1997, Piracicaba. Anais... Piracicaba: Fundação de Estudos Agrários Luiz de Queiroz, 1997. p.123-150.

RUSSELL, J.B.; WILSON, DB. Why are ruminal cellulolytic bacteria unable to digest cellulose at low pH? Journal of Dairy Science, v.79, p.1503-1509, 1996.

SANTOS, E.D.G. Terminação de bovinos em pastagem de Brachiaria decumbens Stapf, durante a estação seca, alimentados com diferentes concentrados. Viçosa, MG: Universidade Federal de Viçosa, 2000. 163p. Dissertação (Mestrado em Zootecnia) - Universidade Federal de Viçosa, 2000.

SILVA, D.J. Análise de alimentos (métodos químicos e biológicos). 2.ed. Viçosa, MG: Universidade Federal de Viçosa, 1990. 165p.

SNIFFEN, C.J.; O’CONNOR, J.D.; Van SOEST, P.J. et al. A net carbohydrate and protein system for evaluating cattle diets: II. Carbohydrate and protein availability. Journal of Animal Science, v.70, n.12, p.3562-3577, 1992. 
TILLEY, J.M.; TERRY, R.A. A two stage technique for the in vitro digestion of forage crops. Journal British Grassland Society, v.18, n.1, p.104-111, 1963.

Van SOEST, P.J.; ROBERTSON, J.B.; LEWIS, B.A. Symposium: carbohydrate methodology, metabolism, and nutritional implications in dairy cattle. Methods for dietary fiber, neutral detergent fiber, and nonstarch polysaccharides in relation to animal nutrition. Journal of Animal Science, v.74, p.3583-3597, 1991.
VIEIRA, P. F. Efeito do formaldeído na proteção de proteína e lipídeos em rações. Viçosa, MG: Universidade Federal de Viçosa, 1980. 98p. Tese (Doutorado em Zootecnia) - Universidade Federal de Viçosa, 1980.

Recebido em: 19/04/02

Aceito em: 20/08/03 